chuyển viện lên tuyến trên do bệnh nặng, bệnh khó, bệnh hiếm gặp còn cao chiếm 9,81\%, tử vong chiếm $1,37 \%$.

\section{KẾT LUẬN}

Qua nghiên cứu, đánh giá mô hình bệnh tật và tử vong trẻ giai đoạn 2011-4/2019 điều trị tại Bệnh viện Đa khoa tỉnh Hà Tĩnh, chúng tôi nhận thấy nhóm bệnh thuộc cơ quan hô hô hẩp, nhiểm khuẩn và tiêu hóa là chủ yếu. Tỷ lệ tử vong chủ yếu ở sơ sinh. Đây là mô hình bệnh tật và tử vong chủ yếu ở các nước đang phát triển.

\section{TÀI LIÊU THAM KHẢO}

1. Nguyễn Công Khanh và CS (2005), "Nghiên cứu xây dựng hệ thống cấp cứu Nhi khoa tại Việt
Nam giai đoạn 2005 - 2015", Đề tài khoa học cấp nhà nước, nghiêm thu 12/2005.

2. Trương Thị Thanh Nhân, Nguyễn Thị Tiến và cộng sự, Tînh hình bệnh tật và tử vong ở trẻ em bểnh viện đa khoa tỉnh Đắk Lắk (1995-1999). Kỷ yểu NCKH 2000 Hội nghị khoa học toàn quốc tháng 11 năm 2000.

3. Trân Thị Minh Hương và CS, Mô hình bệnh tật và tử vong tại khoa nhi bệnh viện Trung Ương Huế 5 năm 2001-2005 trang 11 Kỷ yếu NCKH 2006 Hội nghị Nhi khoa miên trung.

4. Trân Kim Hảo và CS, Mô hình tử vong tại khoa nhi bệnh viện Trung Ương Huế trang 82. Kỷ yếu NCKH 2006 Hội nghị Nhi khoa miền trung.

5. Võ Phương Khanh và CS (2008), "Mô hình bệnh tật tại bệnh viên nhi đồng 2", Y Hoc TP. Ho Chi Minh * Vol. 12 - Supplement of No 4: $92-98$.

\title{
ĐÁNH GIÁ TÌNH TRANG HẠCH VÀ MỘT SỐ YẾU TỐ TIÊN LƯỢNG MÔ BỆnH HỌC CỦA U HẲC TỐ ÁC TÍNH
}

\author{
Nguyễn Văn Chử ${ }^{1,2}$, Trần Lê Giang ${ }^{2}$, Vũ Thanh Phương ${ }^{1}$
}

TÓM TẮT

Việc đánh giá tình trạng hạch của u hắc tỗ ác tính vẫn là sự chuấn mực trong điểu trị và tiên lượng. Typ mô bệnh học và mô tả các đặc điểm mô bệnh học có khả năng cung cấp thông tin quan trọng cho tiên lượng bệnh. Mục tiêu:Nhận xét mối liển quan giữa tình trang hach với một số đặc điểm mô bệnh học của u hắc tố ác tính. Đối tượng và phương pháp nghiên cứu: 121 bệnh nhân u hắc tố ác tính được đánh giá tình trạng hạch, phân typ mô bệnh học và một số đắc điểm giải phẫu bệnh. Kết quả nghiên cứu: Tỷ lệ di căn hạch ở các nhóm tăng theo độ Clark, đăc biệt ở nhóm di căn 2-3 hạch đô Clark V̀ chiếm tỷ lệ cao nhất là 78,6\% tiếp đến là nhóm di căn 1 hạch, Clark $V$ là $69,6 \%$ và nhóm $\geq 4$ hạch là $55,0 \%$ $(p<0,05)$. Khi di căn từ 2-3 hoăc $\geq 4$ hạch, các u hắc tố ác tính không có biểu hiện xẩm nhập lympho u đều chiếm tỷ lệ cao nhất (lần lượt là 17,7 và $21,6 \%)(p<$ 0,05). Kểt luận: Tình trạng hạch có mối liên quan chặt chẽ với độ Clark và sự xâm nhập lympho vào mô u.

Tư khóa: U hắc tố ác tính, Tình trạng hạch, Đặc điểm mô bệnh học.

\section{SUMMARY}

ASSESSMENT OF LYMPH NODE STATUS AND SOME PROGNOSTIC HISTOPATHOLOGICAL

FACTORS OF MALIGNANT MELANOMA

Assessment of the lymph node status of malignant

${ }^{1}$ Bênh viẹn $K$

2Trường Đai hoc Y Hà Nọi

Chịu trách nhiệm chính: Nguyễn Văn Chủ

Email: chunv@bvk.org.vn

Ngày nhân bài: 2.3.2021

Ngày phản biên khoa hoc: 26.4.2021

Ngày duyệt bài: 4.5.2021 melanoma remains the standard of treatment. Histopathological type and features can provide the prognostic information. Purpose: Comment on the relationship between some histopathological features with the lymph node status of melanoma. Methods: 121 melanoma patients were assessed for lymph node status, histopathological subtype and some pathological features. Results: The rate of the metastasized lymph node groups were increased with Clark degrees, especially to the 2-3 node, Clark V was accounted for the highest rate of $78.6 \%$, followed by the positive 1 node group, Clark $\mathrm{V}$ was $69.6 \%$ and $\geq 4$ lymph node group was $55.0 \%$ ( $p<0.05$ ). In $2-3$ or $\geq 4$ metastasized lymph node groups, melanoma without lymphocyte infiltration showed the highest proportion (17.7 and $21.6 \%$, respectively) $(p<0.05)$. Conclusion: The lymph node status of malignant melanoma is strongly related to Clark degree and tumor lymphocytic infiltration.

Key words: Malignant melanoma, Lymph node status, Histopathological characteristic.

\section{I. ĐẶT VẤN ĐỀ}

U hắc tố ác tính là loại ung thư rất ác tính thường biểu hiện lâm sàng là một hình dạng bất thường, không đối xứng với màu sắc khác nhau với một tiền sử gần đây thay đổi về kích thước, hình dạng, màu sắc hay cảm giác. Loại u này rất hay di căn hạch, ngay cả khi u biểu hiện ở da giống như một tổn thương lành tính. U hắc tố ác tính chiếm tỳ lệ tử vong cao nhất trong ung thư da. Việc xác định bệnh nhân có di căn hạch bằng mô bểnh học $(\mathrm{MBH})$ đã đạt được nhiều tiến bộ đáng kể trong hai thập kỷ qua. Trong khi nỗ lực tìm các phương pháp thay thế để dự đoán tiển 
lượng, bao gồm sự bộc lộ gen của khối u ác tính nguyên phát, đã cho thấy nhiều hứa hẹn, tuy nhiên việc đánh giá tình trạng hạch vẫn là sự chuẩn mực cho điêu trị [1]. Đây cũng là những thách thức về chẩn đoán nhất là đối với các bác sĩ giải phẫu bệnh. Việc phân typ $\mathrm{MBH}$ và mô tả các đặc điểm $\mathrm{MBH}$ có khả năng cung cấp thông tin quan trọng cho tiên lượng bệnh. Bề dày khối u, vị trí, typ MBH và có hay không có loét bề mặt da là các chỉ điểm tiên lượng quan trọng [2]. Nhìn chung, tuổi mắc bệnh già tiên lượng kém hơn tuổi trẻ ở các khối u có cùng bề dày, trong khi nữ thường tiên lượng tốt hơn nam. U hắc tố ác tính lan tràn bề mặt tiên lượng tốt hơn so với các typ khác bởi vì chúng thường có độ Breslow thấp [3]. Ở nước ta còn ít công trình nghiên cứu đánh giá sự liên quan giữa tình trạng hạch với các đặc điểm $\mathrm{MBH}$ của u hắc tố ác tính. Vì vậy, chúng tôi tiến hành đề tài này nhằm mục tiều: "Nhận xét mối liên quan giữa tinh trạng hạch với mốt số đặc điểm mô bênh hoc của u thư hắc tố ác tính".

\section{II. ĐỐI TƯợNG VÀ PHƯƠNG PHÁP NGHIÊN CỨU}

Đối tượng nghiên cứu: 121 bênh nhân u hắc tố ác tính của da được điều trị phẫu thuật tại bệnh viện $K$ từ 2013 đến 2020.

\section{Tiêu chuẩn lựa chọn đối tượng}

- Có chẩn đoán MBH là u hắc tố ác tính.

- Bệnh nhân được phẫu thuật cắt $u$ và vét hạch vùng.

- Không được điều trị hóa chất và xạ trị tiền phẫu, có đủ thồng tin lâm sàng.

\section{KẾT QUẢ NGHIÊN CỨU}

\section{Bảng 1. Tình trạng hạch và typ mô bệnh học}

\begin{tabular}{|c|c|c|c|c|c|c|c|}
\hline Hạch & $\mathbf{N}(\mathbf{\%})$ & NOS & $\begin{array}{c}\text { Xuất phát từ } \\
\text { nốt ruối xanh }\end{array}$ & Lentigo & $\begin{array}{c}\text { Lan tràn } \\
\text { bề mặt }\end{array}$ & Thể xơ & \multirow{2}{*}{$\mathbf{p}$} \\
\hline 0 & $64(52,9)$ & $59(52,2)$ & $2(100,0)$ & $2(100,0)$ & $1(33,3)$ & 0 & \\
\cline { 1 - 8 } 0 & $23(19,0)$ & $22(19,5)$ & 0 & 0 & $1(33,3)$ & 0 & \multirow{2}{*}{0,27} \\
\hline $2-3$ & $14(11,6)$ & $13(11,5)$ & 0 & 0 & 0 & $1100,0)$ & \\
\hline$\geq 4$ & $20(16,5)$ & $19(16,8)$ & 0 & 0 & $1(33,3)$ & 0 & \\
\hline Tống & $\mathbf{1 2 1}$ & $\mathbf{1 1 3}(\mathbf{9 3 , 5})$ & $\mathbf{2 ( 1 , 6 )}$ & $\mathbf{2 ( 1 , 6 )}$ & $\mathbf{3 ( 2 , 5 )}$ & $\mathbf{1 ( 0 , 8 )}$ & \\
\hline
\end{tabular}

Nhận xét: Tỷ lệ chưa di căn hạch chiếm tỷ lê cao là 52,9\%; trong các bệnh nhân bị di căn hạch, nhóm di căn $<2$ hạch chiếm tỷ lệ cao nhất là $19,0 \%$, tiếp đến là nhóm di căn $>3$ hạch $(16,5 \%)$ và thấp nhất là nhóm di căn 2-3 hạch $(11,6 \%)$. Typ Lentigo và xuất phát từ nốt ruồi xanh không gặp trường hợp nào di căn hạch (100\%), trái lại typ xơ đều thuộc nhóm di căn 2-3 hạch (100\%). Sự khác biệt không có ý nghĩa thống kê với p>0,05.

\section{Bảng 2. Tình trang hạch và độ Clark}

\begin{tabular}{|c|c|c|c|c|c|c|c|}
\hline Hạch & $\mathbf{N}(\mathbf{\%})$ & I & II & III & IV & V & P \\
\hline 0 & $64(52,9)$ & $1(1,5)$ & $5(7,8)$ & $6(9,4)$ & $25(39,1)$ & $27(42,2)$ & \\
& $23(19,0)$ & $1(4,3)$ & $1(4,3)$ & 0 & $5(21,8)$ & $16(69,6)$ & \multirow{2}{*}{0,049} \\
\hline $2-3$ & $14(11,6)$ & 0 & 0 & 0 & $3(21,4)$ & $11(78,6)$ & \\
\hline$\geq 4$ & $20(16,5)$ & $1(5,0)$ & 0 & $3(15,0)$ & $5(25,0)$ & $11(55,0)$ & \\
\hline Tống & $\mathbf{1 2 1}$ & $\mathbf{3 ( 2 , 5 )}$ & $\mathbf{6 ( 4 , 9 )}$ & $\mathbf{9 ( 7 , 4 )}$ & $\mathbf{3 8 ( 3 1 , 4 )}$ & $\mathbf{6 5}(\mathbf{5 3}, \mathbf{8})$ & \\
\hline
\end{tabular}


Nhận xét: Tỷ lệ di căn hạch ở các nhóm tăng theo độ Clark, đặc biệt nhóm di căn 2-3 hạch độ Clark $V$ chiếm tỷ lẹ cao nhất là $78,6 \%$ tiếp đến là nhóm di căn 1 hạch, Clark $V$ là $69,6 \%$ và nhóm $\geq 4$ hạch là $55,0 \%$. Tiếp đến là Clark IV chiếm vị trí thứ 2 và Clark I chiếm tỷ lệ thấp nhất theo tình trạng hạch. Sự khác biệt được thãy có ý nghĩa thống kê $(p<0,05)$ khi so sánh giữa tình trạng hạch và độ Clark.

\section{Bảng 3. Tình trạng hạch và độ dày Breslow}

\begin{tabular}{|c|c|c|c|c|c|c|}
\hline Hạch & N (\%) & $\leq 1$ & $>1-2$ & $>2-4$ & $>4$ & p \\
\hline 0 & $64(52,9)$ & $1(1,5)$ & $10(15,6)$ & $14(21,9)$ & $39(61,0)$ & \multirow{5}{*}{0,124} \\
\hline 1 & $23(19,0)$ & $1(4,3)$ & $1(4,3)$ & $4(17,5)$ & $17(73,9)$ & \\
\hline $2-3$ & $14(11,6)$ & 0 & 0 & $3(21,4)$ & $11(78,6)$ & \\
\hline$\geq 4$ & $20(16,5)$ & $1(5,0)$ & $1(5,0)$ & $4(20,0)$ & $14(70,0)$ & \\
\hline Tống & 121 & $3(2,5)$ & $12(9,9)$ & $25(20,7)$ & $81(66,9)$ & \\
\hline
\end{tabular}

Nhận xét: Tương tự độ Clark, độ dày Breslow đều chiếm tỷ lệ cao nhất theo tình trạng hạch ở độ xâm nhập sâu >4mm, trong đó cao nhất là nhóm di căn 2-3 hạch (78,6\%), tiếp đên là nhóm di căn 1 hạch $(73,9 \%)$ và di căn $\geq 4$ hạch là $70,0 \%$. Độ dày từ $2-4 \mathrm{~mm}$ chiếm tỷ lệ di căn hạch cao thứ 2 và tỷ lệ di căn hạch thấp nhất ở nhóm có Breslow $\leq 1 \mathrm{~mm}$. Tuy nhiên, sự khác biệt không có ý nghĩa thống kê với $\mathrm{p}>0,05$.

Bảng 4. Tình trạng hạch và tỷ lệ nhân chia

\begin{tabular}{|c|c|c|c|c|c|}
\hline Hạch & $\mathbf{N}(\%)$ & $\mathbf{5 5}$ & $\mathbf{6 - 1 0}$ & $\mathbf{> 1 0}$ & $\mathbf{p}$ \\
\hline 0 & $64(52,9)$ & $37(62,7)$ & $22(45,9)$ & $5(35,8)$ & \\
& $23(19,0)$ & $11(18,6)$ & $9(18,7)$ & $3(21,4)$ & \multirow{2}{*}{0,086} \\
\hline 2 & $14(11,6)$ & $2(3,4)$ & $9(18,7)$ & $3(21,4)$ & \\
\hline$\geq 4$ & $20(16,5)$ & $9(15,3)$ & $8(16,7)$ & $3(21,4)$ & \\
\hline Tống & $\mathbf{1 2 1}$ & $\mathbf{5 9 ( 4 8 , 7 )}$ & $\mathbf{4 8 ( 3 9 , 7 )}$ & $\mathbf{1 4 ( 1 1 , 6 )}$ & \\
\hline
\end{tabular}

Nhận xét: Tỷ lệ nhân chia thấp $(\leq 5)$ chiếm tỷ lệ cao nhất $(52,9 \%)$ so với các nhóm nhân chia khác ở u hắc tố ác tính chưa di căn hạch. Trái lại, tỷ lệ nhân chia cao $(>10)$ đều chiếm tỷ lệ phổ biến ở các nhóm di căn $2-3$ hạch và di căn $\geq 4$ hạch, đêu là $21,4 \%$. Tuy nhiên, những khác biệt này không được thấy có ý nghĩa thống kê $(p>0,05)$.

Bảng 5. Tình trạng hạch và sự xâm nhập lympho u

\begin{tabular}{|c|c|c|c|c|c|}
\hline Hạch & $\mathbf{N}(\%)$ & Âm tính & Không nhiêuu & Nhiêuu & \multirow{2}{*}{$\mathbf{P}$} \\
\hline 0 & $64(52,9)$ & $19(37,2)$ & $34(64,2)$ & $11(64,7)$ & \\
& $23(19,0)$ & $12(23,5)$ & $7(13,2)$ & $4(23,5)$ & \multirow{2}{*}{0,013} \\
\hline 1 & $14(11,6)$ & $9(17,7)$ & $4(7,5)$ & $1(5,9)$ & \\
\hline $2-3$ & $20(16,5)$ & $11(21,6)$ & $8(15,1)$ & $1(5,9)$ & \\
\hline Tốn & $\mathbf{1 2 1}$ & $\mathbf{5 1 ( 4 2 , 1 )}$ & $\mathbf{5 3 ( 4 3 , 8 )}$ & $\mathbf{1 7 ( 1 4 , 1 )}$ & \\
\hline
\end{tabular}

Nhận xét: Các mức độ xâm nhập lympho u đều chiếm tỷ lệ cao nhất nhóm chưa di căn hạch, trong đó nhóm u thư hắc tố ác tính có xẩm nhập nhiều lympho bào chiếm tỷ lệ cao nhất là $64,7 \%$. Trái lại, khi di căn từ 2-3 hoăc $\geq 4$ hạch, các $u$ thư hắc tố ác tính không có biểu hiện xâm nhập lympho u đều chiếm tỷ lệ cao nhất (lần lượt là 17,7 và $21,6 \%$ ). Sự khác biệt được thấy có ý nghĩa thống kê $(p<0,05)$ khi so sánh giữa tình trạng hạch và mức độ xâm nhập lympho bào vào mô u.

\section{BÀN LUÂN}

Tình trạng hạch: U hắc tố ác tính ở da đặc trưng lây lan qua hệ thống bạch huyết từ vị trí nguyên phát của nó đến các hạch bạch huyết vùng. Sự hiểu biết về tình trạng hạch rất quan trọng để tiên lượng và xác định liệu pháp toàn thân bổ trợ sự phù hợp. Ở những bệnh nhân có nguy cơ di căn hạch bạch huyết vùng (u hắc tố có độ dày $>0,8 \mathrm{~mm}$ và u hắc tố mỏng hơn nhất định, đặc biệt là những bệnh nhân bị loét hoặc > 1 nhân chia/mm2), lập bản đồ bạch huyết với sinh thiết hạch cửa là một thành phần quan trọng của phương pháp tiếp cận theo chia giai đoạn chuẩn [1]. Trong nghiên cứu của chúng tôi, theo bảng 1 cho thấy trong 121 bệnh nhân u hắc tố ác tính, tỷ lệ di căn hạch chiếm $47,1 \%$, trong đó nhóm di cắn <2 hạch chiếm tỷ lệ cao nhất là $19,0 \%$, tiếp đến là nhóm di căn $>3$ hạch $(16,5 \%)$ và thấp nhất là nhóm di căn $2-3$ hạch $(11,6 \%)$. Trong số các bệnh nhân bị di căn hạch trong nghiên cứu của chúng tôi cho thấy người bị di căn nhiều nhất là 18 hạch. Trái lại, một số nghiên cứu cho thây tỷ lệ di căn hạch là $21,7 \%$ [6], thấp hơn của chúng tôi.

Tình trạng hạch và đặc điểm mô bệnh học: Dựa vào các đặc điểm lâm sàng và GPB 
của một loạt các nghiên cứu về u hắc tố ác tính nguyên phát cũng như hồi cứu y văn, Clark đã đề xuất một bảng phân loại, đầu tiên dựa vào sự có hay khổng có giai đoạn phát triển lan tỏa và dưa vào hình thái của chúng [4]. Cùng thời điểm, McGovern đã đề xuất một bảng phân loại tương tự [5]. Bảng phân loại được phát triển hớn nữa đã được tái khẳng định bởi hội nghị quốc tế gần đây $[2,6]$. Trong nghiên cứu của chúng tôi, theo bảng 1 cho thấy typ Lentigo và xuất phát từ nốt ruồi xanh không gặp trường hợp nào di căn hach $(100 \%)$, trái lại typ xơ đều thuộc nhóm di căn 2-3 hạch (100\%).

Mức độ xâm nhập: được xác định bởi Clark đã được sử dụng trên 40 nămm để xếp giai đoạn u hắc tố ác tính [4]. Phân giai đoạn T của u hắc tố ác tính được phân loại chủ yếu bằng sự đo bề dày của khối u, được xác định bởi Breslow [7]. Đánh giá mức độ Clark được coi là quá chủ quan đối với xếp giai đoạn nển $A J C C$ ấn bản mới nhất đã loại bỏ độ Clark $[5,6,7,8]$. Trong nghiên cứu của chúng tôi, theo bảng 2 cho thấy tỷ lệ di căn hạch ở các nhóm tăng theo độ Clark, đặc biệt nhóm di căn 2-3 hạch độ Clark V chiếm tỷ lệ cao nhất là $78,6 \%$ tiếp đến là nhóm di căn 1 hạch, Clark $V$ là $69,6 \%$ và nhóm $\geq 4$ hạch là $55,0 \%$. Tiếp đến là Clark IV chiếm vị trí thứ 2 và Clark I chiếm tỷ lệ thấp nhất theo tình trạng hach $(p<0,05)$.

Độ dày Breslow theo định nghĩ của Breslow năm 1969, độ dày được đo từ đỉnh lớp hạt tới vùng tế bào u xâm nhẩp sâu nhất [7]. Nếu tính riêng, độ dày Breslow là yếu tố tiên lượng mạnh nhất trong u hắc tố ác tính. Kết quả nghiên cứu của chúng tôi (bảng 3) cho thấy tương tự độ Clark, độ dày Breslow đều chiếm tỷ lê cao nhất theo tình trang hạch ở độ xâm nhập sâu $>4 \mathrm{~mm}$, trong đó cao nhất là nhóm di căn 2-3 hạch $(78,6 \%)$, tiếp đến là nhóm di căn 1 hạch $(73,9 \%)$ và di căn $\geq 4$ hach là $70,0 \%$. Đố dày từ $2-4 \mathrm{~mm}$ chiếm tỷ lệ di cắn hach cao thứ 2 và tỷ lệ di căn hạch thấp nhất ở nhóm có Breslow $\leq 1 \mathrm{~mm}$.

Chỉ số nhân chia: trong nghiên cứu của Clark năm 1989 từ các bệnh nhân bị u hắc tố ác tính giai đoan phát triển theo chiều dọc, chỉ số nhân chia là yếu tố tiên lượng mạnh, đơn thuần. Các bệnh nhân có $\geq 6$ nhẩn chia có nguy cơ di căn cao gấp 20 lần các bệnh nhân có khối u không có nhân chia. Hơn nữa, sự có bất kỳ nhân chia ở trung bì dự báo không chỉ thời gian sống thêm mà còn dự báo khả năng di căn hạch cửa [4]. Trong nghiên cứu của chúng tôi (bảng 4), số lương nhân chia được chia thành 3 nhóm $\leq 5$, chiếm $48,7 \%$, nhóm $6-10$ nhân chia là $39,7 \%$ và nhóm >10 nhân chia chiếm $11,6 \%$, trong đó bệnh nhân có số lượng nhân chia nhiều nhất ở vi trường hotpot là 20 . Khi đánh giá tình trạng hạch theo các nhóm nhân chia, chúng tôi nhận thấy rằng tỷ lệ nhân chia thấp $(\leq 5)$ chiếm tỷ lệ cao nhất $(52,9 \%)$ so với các nhóm nhân chia khác ở u hắc tố ác tính chưa di căn hạch. Trái lại, tỷ lệ nhân chia cao $(>10)$ đều chiếm tỷ lệ phổ biến ở các nhóm di căn 2-3 hạch và di căn $\geq 4$ hạch, đều là $21,4 \%$. Kết quả này phủ hợp với một số nghiên cứu đã được công bố trước đây $[3,6]$.

Xâm nhập lympho vào mô u: đầu tiên được chứng minh bởi nghiên cứu của Clark và sau đó tiếp tục được khẳng định bởi các nghiên cứu khác, sự xâm nhập lympho vào mô u mạnh (các tế bào lympho ở giữa và liên tục với các tế bào u) hầu như có giá trị tiên lượng mạnh như chỉ số nhân chia [7]. Trong nghiên cứu của chúng tôi, theo bảng 5 cho thấy các mức độ xâm nhập lympho u trong ung thư hắc tố gồm các mức: không xâm nhập, xâm nhập ít và xâm nhập nhiều với tỷ lệ lần lượt là 42,$1 ; 43,8$ và $14,1 \%$. Các mức độ xâm nhập lympho vào mô u đều chiếm tỷ lệ cao nhất nhóm chưa di căn hạch, trong đó nhóm ung thư hắc tố có xâm nhập nhiều lympho bào chiếm tỷ lệ cao nhất là $64,7 \%$. Trái lại, khi di căn từ 2-3 hoăc $\geq 4$ hạch, các u hắc tố ác tính không có biểu hiện xâm nhập lympho u đều chiếm tỷ lệ cao nhất (lần lượt là $17,7$ và $21,6 \%)$.

\section{KẾT LUÂ̂N}

Qua nghiên cứu đặc điểm giải phẫu bệnh của 121 mẫu u hắc tố ác tính và đánh giá tình trạng hạch chúng tôi rút ra các kết luận sau: Tình trạng hạch có mối liên quan chặt chẽ với độ Clark và sự xâm nhập lympho vào mô u. Tuy nhiên, mối liên quan giữa tình trạng hạch và typ mô bệnh học, tỷ lệ nhân chia, độ dày Breslow chưa có ý nghĩa thống kê.

\section{TÀI LIÊU THAM KHẢO}

1. Stebbins W, Garibyan L, Sober AJ: Sentinel lymph node biopsy and melanoma: 2010 update Part I. J Am Acad Dermatol 2010, 62:723.

2. Balch: C.M, Buzaid A.C, Soong S.J et al (2001). Final version of the American Joint Committee on Cancer staging system for cutaneous melanoma. J Clin Oncol 19: 3635-3648.

3. MacKie: R.M (2000). Malignant melanoma: clinical variants and prognostic indicators. Clin Exp Dermatol 25: 471-475.

4. Clark: W.H (1967). A classification of malignant melanoma in man correlated with hyitogenesis and biologic behavior. In: Advances in the biology of the skin; vol VIII. New York: Peramon Press: 621-47.

5. McGovern: Mihm MC, Bailly C, et all (1973) 
The classification of malignant melanoma and its histologic reporting Cancer;32:1446-57.

6. Richard A Scolyer RA, Long GV and Thompson JF (1967). Moles and malignant melanoma: terminology and classification. Med J Aust; 1:123-5.
7. Breslow: A (1975). Tumor thickness, level of invasion and node dissection in stage I cutaneous melanoma. Ann Surg;182: 572-5.

8. Fleming: I.D, Greene FL, Page $D L$, et al (2010). AJCC Cancer Staging Manual, 7th edition. New York: Springer-Verlag.

\section{KHẢO SÁT MỨC Độ THÍCH ỨNG ĐỐI VỚI HOẠT ĐộNG HỌC TÂPP CỦA SINH VIÊN NĂM THỨ NHẤT KHOA XÉT NGHIỆM TRƯỜ'NG ĐẠI HỌC KỸ THUÂTT Y TẾ HẢI DƯƠ'NG.}

\section{TÓM TẮT}

Muc tiêu: Khảo sát mức đô thích ứng đối với hoat động học tâp của sinh viên năm thứ nhất khoa Xét nghiệm trường Đại học Kỹ thuật $Y$ tế Hải Dương và một số yếu tố ảnh hưởng. Phương pháp: Nghiên cứu ngang có phân tích. Kết quả: Thích ứng đối với hoạt động học tập của sinh viên năm thức nhất khoa Xét nghiệm trường Đại học Kỹ thuật $Y$ tế Hải Dương đạt ở mức thích ứng trung bình $(93,4 \%)$. Trong nhóm thích ứng trung bình có $40,2 \%$ sinh viên có kết quả học tập trung bình, 34,4\% sinh viên có kết quả khá, $0,8 \%$ sinh viên có kêt quả giỏi. Sinh viên còn gặp nhiều khó khăn trong việc theo kịp tiến độ học đại học, tỉ lệ sinh viên hài lòng với kết quả học tập và tình hình học tập của bản thân còn thấp. Trong các nhóm yếu tố ảnh hưởng tới mức độ thích ứng đối với học tập thì yếu tố bản thân sinh viển được đánh giá là ảnh hưởng nhiều nhất.

\section{SUMMARY}

\section{THE SURVEY OF ADAPTATION TO LEARNING ACTIVITIES OF THE FIRST- YEAR STUDENTS IN THE LABORATORY DEPARTMENT OF HAI DUONG MEDICAL TECHNICAL UNIVERSITY}

Objective: Survey of adaptation to learning activities of the first-year students in the Laboratory Department of Hai Duong Medical Technical University and a number of influencing factors. Subjects and methods: Cross-sectional survey. Results: The average adaptation to learning activities of the firstyear students in the Laboratory Department of Hai Duong Medical Technical University was $93,4 \%$. In the average adaptation group, $40,2 \%$ of students have average results and $0,8 \%$ of sudents have excellent results. Students still face many difficulties in keeping up with the progress of studying at university, the rate

*Trường Đại học Kỹ thuật Y tế Hải Dương

Chịu trách nhiệm chính: Mạc Thị Thảo

Email: thaomac.hmtu@gmail.com

Ngày nhận bài: 3.3.2021

Ngày phản biên khoa học: 19.4.2021

Ngày duyệt bài: 28.4.2021

\section{Mạc Thị Thảo*, Nguyễn Thị Kiều Liên*, Nguyễn Thị Nga*, Phạm Thị Thùy Nhu**}

of students satisfied with their study outcome and their learning situation is still low. Among the groups of factors that affected the adaptive level of learning, the factors that students themselves are considered to be the most influential.

\section{I. ĐĂT VẤN ĐỀ}

Tại Việt Nam hiện nay, giáo dục đại học đang là vấn đề được cả xã hội quan tâm. Giảng đường đại học là bước ngoặt iớn đối với mỗi sinh viên, đặc biệt là sinh viên năm thứ nhất. Cuộc sống ở trường đại học cho sinh viên năm đầu tiên đây thú vị nhưng cũng đầy thử thách. Một mặt, sinh viên năm thứ nhất sẽ thấy tự do hơn nhưng mặt khác họ sẽ phải tổ chức lại hoạt động học tập, xây dựng lại những mối quan hể cá nhân trong một môi trường mới và điều đó có thể gây ra những căng thẳng. Thích ứng tâm lý kém với môi trường đại học có thể buộc sinh viên phải rời khỏi trường. [1]

Thích ứng với hoạt động học tập là một yêu câu bắt buộc đối với sinh viên, đặc biệt là sinh viên năm đầu tiên. Đó chính là quá trình sinh viên tích cực chủ động làm quen, hòa nhập vào các điều kiện học tập mới khác về chất so với hoạt động học tập trong trường trung học phổ thông nhằm hình thành và phát triển nhân cách nghề nghiệp tương lai, thực hiện hiệu quả mục tiêu đào tạo của nhà trường và đáp ứng yêu cầu của xã hội hiện đại. [2]

Phần lớn sinh viên năm thứ nhất khoa Xét nghiệm trường Đại học Kỹ thuật $Y$ tế Hải Dương đều mới tốt nghiệp bậc học phổ thông. Sự chuyển tiếp này đã̉ tạo ra rất nhiều khác biệt trong hoạt động học tập như khối lượng, nội dung tri thức, phương pháp giảng dạy. Trường Đại học kỹ thuật $Y$ tế Hải Dương là một trong những trường đầu tiên thuộc khối ngành sức khoẻ giảng dạy theo học chế tín chỉ. Đào tạo theo học chế tín chỉ là mô hình đào tạo mới đối 